\title{
A Combination of Virgin Coconut Oil and Extra Virgin Olive Oil Elicits Superior Protection Against Doxorubicin Cardiotoxicity in Rats
}

\author{
(1) Andi Ulfiana UTARI ${ }^{1}$, (1) Yulia Yusrini DJABIR ${ }^{1 *}$, (1) Bogie Putra PALINGGI2 \\ ${ }^{1}$ Hasanuddin University, Faculty of Pharmacy, Department of Pharmacy, Makassar, Indonesia \\ 2Labuang Baji Province General Hospital, Clinic of Cardiology and Vascular Medicine, Makassar, Indonesia
}

\begin{abstract}
Objectives: The use of the chemotherapy agent doxorubicin (DOX) is associated with free radical formation that may lead to cardiotoxicity. Virgin coconut oil (VCO) and extra virgin olive oil (EVOO) are plant-based oil that is rich in antioxidants. This study examined the protective effects of VCO and EVOO combination to reduce DOX acute cardiotoxicity in rats.

Materials and Methods: Twenty-five male rats (180-200 g) were divided into the following groups: Group I as a control, group II was given DOX i.p. injection of $25 \mathrm{mg} / \mathrm{kg}$ body weight (b.w.), group III to V received peroral administration of either VCO, EVOO or VCO-EVOO (1:1) combination at a dose of $10 \mathrm{~mL} / \mathrm{kg}$ b.w. for 6 days before receiving DOX i.p. injection. After 24 hours from DOX injection, blood samples and organs were collected. Cardiac biomarkers, such as serum glutamic-oxaloacetic transaminase (SGOT), lactate dehydrogenase (LDH), and creatine kinase-MB (CKMB) were analyzed followed by histopathological examination.

Results: The administration of EVOO alone was found to reduce the marked elevation of SGOT, LDH, and CKMB levels in DOX-treated rats ( $p<0.05$ ), while VCO administration only significantly reduced LDH and CKMB levels. However, when both oils were used in combination, the protective effect was shown to be more powerful since all cardiac biomarker levels were maintained at near-normal levels ( $p<0.05)$. Histopathological analysis showed a significant improvement in the myocardial tissue structures after pre-treatment with VCO-EVOO combination.

Conclusion: The administration of VCO and EVOO in combination was superior to elicit protection against DOX-induced cardiotoxicity compared to their individual application in rats.
\end{abstract}

Key words: Doxorubicin, cardiac toxicity, virgin coconut oil, extra virgin olive oil

\section{INTRODUCTION}

Doxorubicin (DOX) is an anthracycline isolated from Streptomyces peucetius var. caesius in the 1970s.' DOX has been widely used for treating various malignancies, including breast and lung cancers, lymphomas, myeloma, and sarcomas. ${ }^{2}$ However, clinical studies have reported approximately $3-33 \%$ of patients, who received DOX developed subclinical cardiomyopathy and some progress to congestive heart failure, even with an average cumulative dose of $300 \mathrm{mg} / \mathrm{m}^{2.3,4}$

The mechanism of DOX toxicity is mediated by the metabolic conversion of DOX to its secondary alcohol doxorubicinol. ${ }^{5}$ This metabolite then interacts with iron and initiates the formation of reactive oxygen species (ROS) that subsequently damage cellular macromolecules. ${ }^{6}$ DOX can also form semiquinone radical intermediates that react with oxygen to produce superoxide anion radicals, which in turn produce hydrogen peroxide and hydroxyl radicals that mostly attack lipids, proteins, and DNA molecules. ${ }^{7}$ As a result, DOX-treated patients are at high risks of experiencing cardiotoxicity.

Bioactive compounds that can protect the heart against cardiotoxicity have been continuously pursued over the past few decades. Virgin coconut oil (VCO) and extra virgin olive oil (EVOO) are two different plant-based oils that provide health benefits to cardiac tissue and function. VCO contains 
antioxidants mostly in the form of polyphenols, which have the capability to inhibit low-density lipoprotein (LDL) oxidation in rats. ${ }^{8}$ In separate studies, VCO or EVOO administration increases antioxidant enzyme activities and improve the body's defense system against oxidative stress., ${ }^{910}$ Moreover, the hydroxytyrosol and oleuropein content of EVOO can act as free radical scavengers and inhibit the oxidation of LDL.1 Accordingly, this study compared the cardioprotective effects of VCO, EVOO, and their combination (1:1) on DOX-induced cardiotoxicity in rats.

\section{MATERIALS AND METHODS}

\section{Materials}

VCO (Avcol ${ }^{\circledR}$, Indonesia) and EVOO (CV. Asy Syifa, Indonesia) used in this study are registered in the Indonesian Food and Drug Administration and were purchased from a registered pharmacy. DOX HCl $50 \mathrm{mg} / 25 \mathrm{~mL}$ (Kalbe Farma, Indonesia) and sodium chloride $(\mathrm{NaCl}) 0.9 \%$ were obtained from a local hospital.

\section{Animals}

Male Wistar rats weighed at 180-200 g $(n=25)$ were procured from a laboratory animal breeder in Makassar, Indonesia. The animals were cared for in a laboratory with a 12 hour dark/light cycle and provided with food and drink daily. The animals were acclimatized to laboratory environmental conditions for 14 days before the experiment was carried out. All animal protocols were performed based on institutional guidelines for animal laboratory handling and registered under an institutional ethical clearance number of UH21020059 from the Ministry of National Education, University of Hasanuddin Faculty of Medicine, Health Research Ethics Committee.

\section{Experimental design}

A simplified scheme of the experimental protocol is illustrated in Figure 1. The rats were divided into 5 groups where each group consisted of 5 rats. Rats' blood samples $(3 \mathrm{~mL})$ were withdrawn before treatment initiation to provide serum biomarker baseline levels. Group I as a control group was intraperitoneally (i.p.) injected with $0.9 \% \mathrm{NaCl}$ solution as a placebo, while group II was i.p. injected with $25 \mathrm{mg} / \mathrm{kg}$ b.w. of DOX on the $7^{\text {th }}$ day of the experiment. Group III to $\mathrm{V}$ received pre-treatments of either VCO $(10 \mathrm{~mL} / \mathrm{kg})$, EVOO $(10 \mathrm{~mL} / \mathrm{kg})$, or VCO-EVOO (1:1 at $10 \mathrm{~mL} / \mathrm{kg}$ dose), respectively. The oil treatment was administered using an oral cannula for 6 days, before receiving DOX i.p. injection on the next day. After $24 \mathrm{~h}$ from DOX injection, rats were anesthetized with diethyl ether, and $3 \mathrm{~mL}$ of blood samples were obtained from lateral veins using vacutainer tubes containing ethylenediaminetetraacetic acid. Blood samples were centrifuged (Hettich ${ }^{\circledR}$ ) at a speed of $2000 \mathrm{rpm}$ for $25 \mathrm{~min}$. The serum was collected immediately and stored at $-20^{\circ} \mathrm{C}$ until biomarker analysis was performed. The experimental protocols used in this study was based on Djabir et al. ${ }^{12}$ study which also delivered a short-term pretreatment to protect against cardiotoxicity induced by a single i.p. injection of DOX $(25 \mathrm{mg} / \mathrm{kg})$. A short-term pre-treatment with VCO $(10 \mathrm{~mL} / \mathrm{kg} /$ day $)$ for 7 days was shown to significantly reduce paracetamol-induced hepatotoxicity. ${ }^{13}$ Meanwhile, pretreatments with EVOO phytochemicals, such as oleuropein or hydroxytyrosol, for up to 7 days sufficiently elicit protection against a range of drug-induced cardiotoxicities. . $^{14-16}$

\section{Biomarker analysis}

The levels of serum glutamic oxaloacetic transaminase (SGOT), lactate dehydrogenase (LDH), and plasma biomarker creatine kinase-MB (CKMB) were analyzed using diagnostic

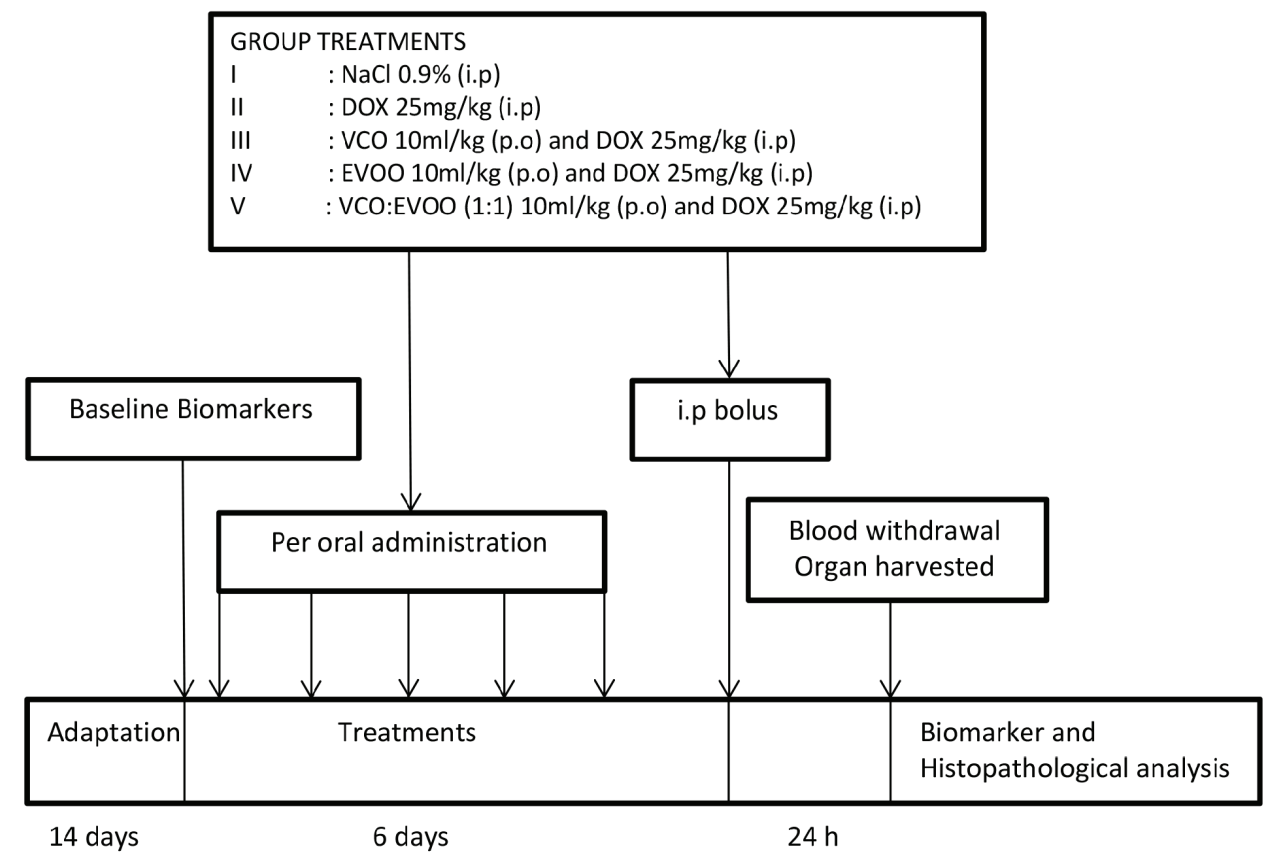

Figure 1. The scheme of experimental protocols 
kits obtained from Human Diagnostic World (Germany). All analytical procedures were carried out according to the kits' instructions. The absorbance was measured using Humalyzer 3500 (Human Diagnostic World) instrumentation.

\section{Histopathological examination}

Following a blood sample collection, rats were euthanized using a cervical dislocation method. The heart was carefully removed and fixated in 10\% formalin in phosphate buffer saline and embedded in paraffin blocks. Sections of $5 \mu \mathrm{m}$ thick were serially sliced with a microtome and stained with hematoxylin and eosin. The microscopic observation of the longitudinal section of the heart tissue was performed by a veterinary pathologist, especially in the area of the ventricles, using a light microscope (Olympus ${ }^{\circledR}$ ) at $40 \mathrm{X}$ magnification.

\section{Statistical analysis}

The numerical data were presented as mean \pm standard error of the mean. The distribution of data normality was tested using a Shapiro-Wilk normal distribution analysis. Normally distributed data were then analyzed with One-Way ANOVA followed by a post-hoc Tukey's honestly significant difference test. Statistical analysis was declared significant if the $p$ value was below 0.05 $(p<0.05)$.

\section{RESULTS}

\section{Biomarker analysis}

The result of cardiac biomarker analysis is illustrated in Figure 2. The healthy control did not show significant changes in the CKMB, LDH, and SGOT levels after receiving $0.9 \% \mathrm{NaCl}$ injection as a placebo (Figure 2). However, in the DOX group, marked increases in CKMB, LDH, and SGOT levels were experienced in all rats. The CKMB, LDH, and SGOT levels of the DOX group were at least three times their baseline values, and this biomarker upsurge was detected as soon as 24 hours from DOX i.p. injection at a dose of $25 \mathrm{mg} / \mathrm{kg} \mathrm{b.w.} \mathrm{(} p<0.01)$.

Apart from the DOX group, the VCO treatment group also experienced an increase in SGOT value after receiving DOX injection, which was significantly higher than the control group ( $p$ <0.01). The other cardiac biomarkers, such as LDH and CKMB levels, also rose about $50 \%$ above the normal control; nevertheless, the statistical analysis did not reach a significant difference compared to the control group.

The administration of EVOO at $10 \mathrm{~mL} / \mathrm{kg}$ resulted in a nearnormal level of CKMB similar to the control group (298 $\pm 33 \mathrm{vs}$. $214 \pm 40 \mathrm{mg} / \mathrm{dL}$ ). However, the LDH level of the EVOO group increased twice as much as that of the normal controls (597 \pm 98 vs $218 \pm 98 \mathrm{mg} / \mathrm{dL}$ ); yet, it was found not statistically significant. The SGOT level also significantly increased in the EVOO group, but it was still significantly lower than that of the DOX-treated animals ( $p$ <0.05). In contrast, the administration of VCO-EVOO combination prevented the increase in CKMB and $\mathrm{LDH}$, resulting in normal biomarker levels. Even though the elevation of SGOT level was still experienced by the VCOEVOO group, it was significantly attenuated compared to the DOX group ( $p<0.05)$.

\section{Histopathological examination}

The normal control that was not subjected to the DOX injection showed regular cardiac myocyte shapes and structures (Figure $3 \mathrm{~A} 1$ ). The bands and nucleus of cardiac myocytes and the myofibrils were clearly clear. There were barely inflammatory cells or necrotic damage found in the area of myocytes. In contrast, the DOX group experienced mild-to-moderate histopathological injuries. Histopathological changes in the heart muscle cells were evident and profound in the area of myocytes. Moderate damage was observed in most DOX-treated rats, which was characterized by hyper-eosinophilic cytoplasm and necrotic cell nuclei, myocardial cell atrophy, loss of nuclei, myolysis, infiltration of inflammatory cells, and hemorrhagic area (Figure 3B1-B3).

Figure 4 shows the representative microscopic images of cardiomyocyte histopathological changes found in rats treated with VCO, EVOO, or their combination. In the VCO-treated rats (Figure 4C1, C2), most cardiac sections showed necrotic cells
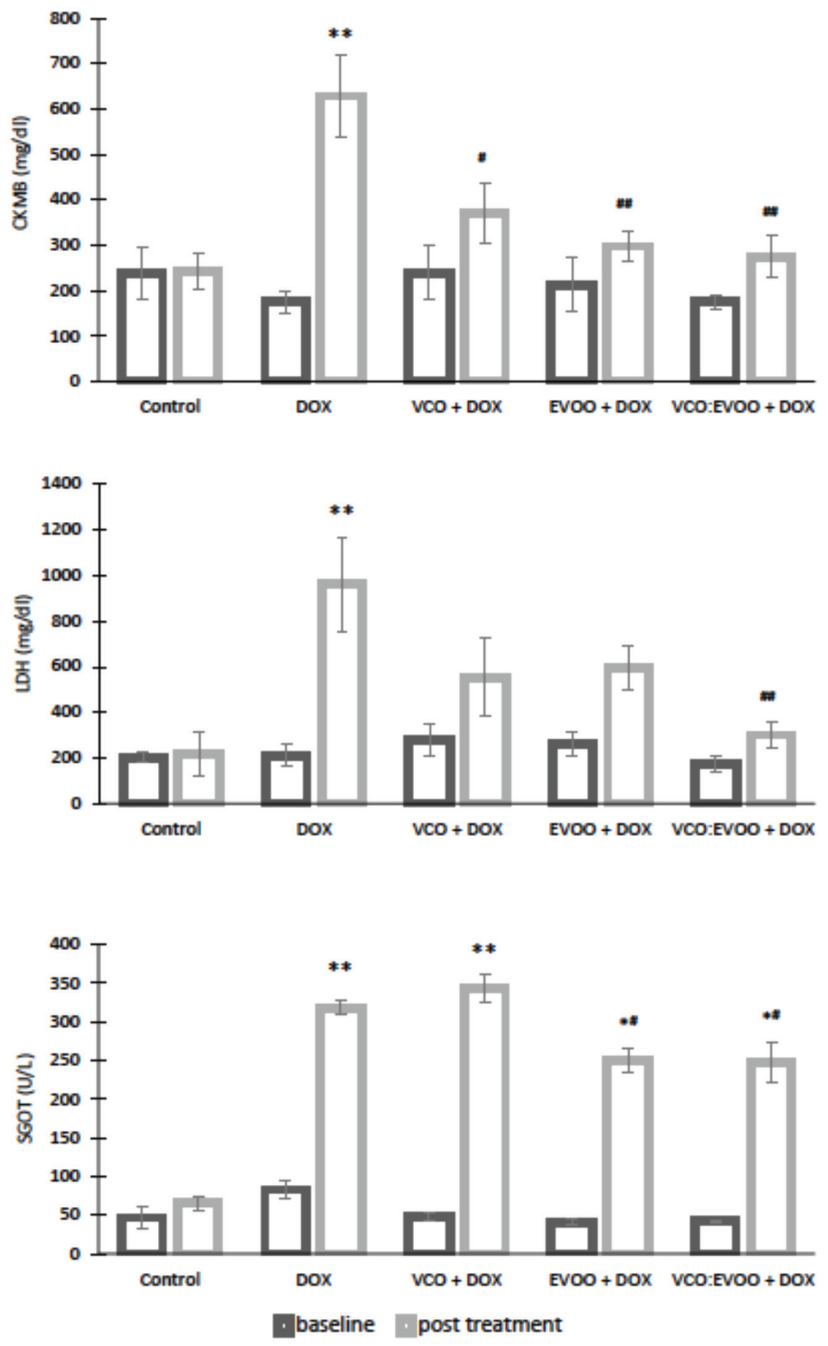

Figure 2. Comparison of creatine kinase-MB, lactate dehydrogenase, and serum glutamic-oxaloacetic transaminase levels between treatment groups at baseline and post-treatment

DOX: Doxorubicin, VCO: Virgin coconut oil, EVOO: Extra virgin olive oil ${ }^{*} p=0.05$ compared to control. $p=0.05$ compared to DOX group 

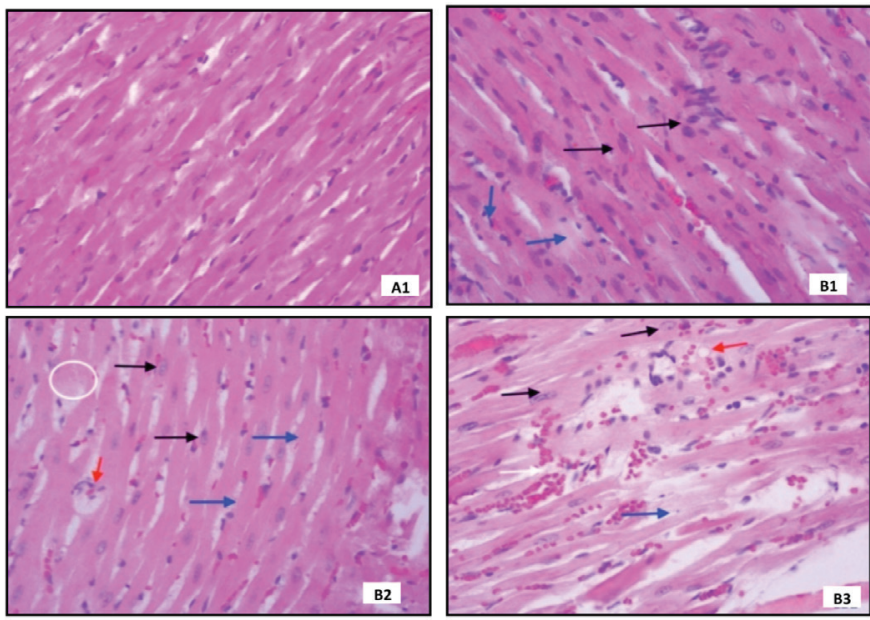

Figure 3. Representative of microscopic images of cardiac tissues in the control and DOX-treated rats. The control (A1) showed normal architecture of myocytes. cells with a normal structure with a magnification of 40X. The DOX group (B1, B2, and B3) showed necrotic cells (black arrow), myocardial muscle atrophy (blue arrow), vacuolar degeneration and hemorrhage (red arrow), and myolysis (white)

DOX: Doxorubicin
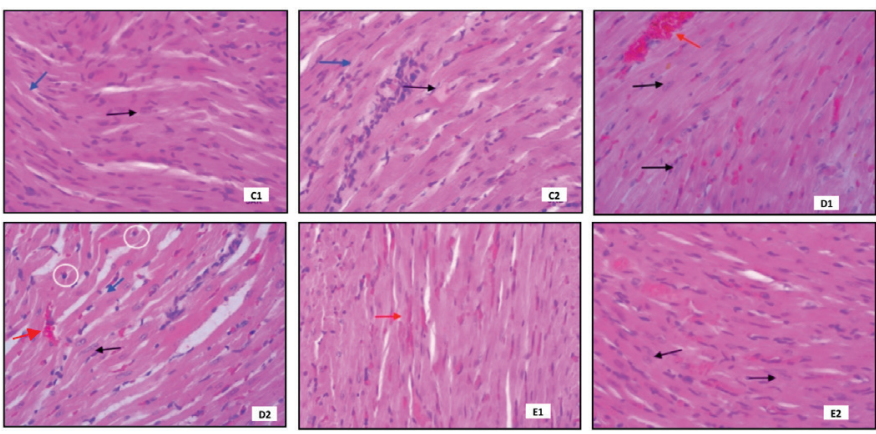

Figure 4. Representative of microscopic images of cardiac tissues in DOX treated rats that received pre-treatment with VCO (C1-2), EVOO (D1-2), and VCO-EVOO (E1-2). Necrotic myocardial cells (black arrow), muscle atrophy (blue arrow), inflammatory cells (white circle), and hemorrhagic area (red arrow)

DOX: Doxorubicin, VCO: Virgin coconut oil, EVOO: Extra virgin olive oil

and cardiomyocyte atrophy. The degree of myocardial injury was found mild to moderate (Table 1). With EVOO pre-treatment, the injection of DOX still resulted in mild-to-moderate damage, shown by the presence of necrotic cells, atrophy of cardiomyocytes, and inflammatory cells in cardiac tissue of rats (Figure 4D1, D2). Conversely, the administration of VCO and EVOO combination could reduce the presence of myocardial pathological damage. In this group, some histopathological changes were found, including hemorrhage and necrotic cells, but the degree was minimal (Figure 4E1, E2). Only two of five animals in this group had minimal myocardial damage, while the three others did not elicit myocardial injury similar to that observed in the normal controls (Table 1).

\section{DISCUSSION}

In spite of its chemotherapy benefit, the use of the DOX regimen is closely related to increased incidence of cardiotoxicity in
Table 1. Histopathological changes and scores found in each animal in the treatment groups

Groups

Rat Histopathological changes (score)

A1 None (0)

A2 None (0)

Control

A3 None (0)

A4 None (0)

A5 None (0)

B1

Necrotic cells and atrophy of cardiomyocytes (2)

B2 Necrotic cells, vacuolization, atrophy of cardiomyocytes, and myolysis (3)

Necrotic cells, atrophy of

DOX

B3 cardiomyocytes, vacuolar degeneration, and hemorrhage (3)

Necrotic cells, atrophy of

B4 cardiomyocytes and inflammatory cells (2)

55 Necrotic cells and atrophy of cardiomyocytes (2)

\begin{tabular}{|c|c|c|}
\hline \multirow{5}{*}{ VCO + DOX } & $\mathrm{C} 1$ & $\begin{array}{l}\text { Necrotic cells and atrophy of } \\
\text { cardiomyocytes ( } 2 \text { ) }\end{array}$ \\
\hline & $\mathrm{C} 2$ & $\begin{array}{l}\text { Necrotic cells and atrophy of } \\
\text { cardiomyocytes ( } 2 \text { ) }\end{array}$ \\
\hline & $\mathrm{C} 3$ & Necrotic myocardial cells (1) \\
\hline & $\mathrm{C} 4$ & $\begin{array}{l}\text { Cardiomyocyte degeneration and } \\
\text { inflammatory cells (1) }\end{array}$ \\
\hline & C5 & Cardiomyocyte degeneration (1) \\
\hline \multirow{5}{*}{ EVOO + DOX } & $\mathrm{D} 1$ & $\begin{array}{l}\text { Cardiomyocyte degeneration and } \\
\text { hemorrhage (1) }\end{array}$ \\
\hline & $\mathrm{D} 2$ & $\begin{array}{l}\text { Necrotic cells, atrophy of } \\
\text { cardiomyocytes and inflammatory cells } \\
\text { (2) }\end{array}$ \\
\hline & D3 & $\begin{array}{l}\text { Necrotic cells and atrophy of } \\
\text { cardiomyocytes ( } 2 \text { ) }\end{array}$ \\
\hline & D4 & $\begin{array}{l}\text { Cardiomyocyte degeneration and } \\
\text { hemorrhage (1) }\end{array}$ \\
\hline & D5 & $\begin{array}{l}\text { Necrotic cells, atrophy of } \\
\text { cardiomyocytes and inflammatory cells } \\
\text { (1) }\end{array}$ \\
\hline \multirow{5}{*}{ VCO: EVOO + DOX } & E1 & Mild hemorrhage (1) \\
\hline & E2 & Degenerative cells (1) \\
\hline & E3 & None $(0)$ \\
\hline & E4 & None (0) \\
\hline & E5 & None (0) \\
\hline
\end{tabular}

The level of damage was none to minimal (0), mild (1), moderate (2), and intense (3). DOX: Doxorubicin, VCO: Virgin coconut oil, EVOO: Extra virgin olive oil 
cancer patients. ${ }^{17}$ Consequently, various research is imposed in the pursuit of cardioprotective agents that can impede DOXinduced toxicity, including olive oil, ${ }^{18}$ taurine, ${ }^{19}$ vitamin $E,{ }^{20}$ and vitamin C..$^{21,22}$ The progression of DOX cardiotoxicity is instigated by the formation of free radicals in the metabolic process of the chemotherapy agent, leading to impaired calcium transport in the sarcolemma, increased production of lipid peroxides, and the release of TNF-, interleukin-2, and free cytokines. ${ }^{23}$ In this study, the administration of DOX was employed to trigger cardiotoxicity in rats. A previous study has shown that DOX i.p. injection $(25 \mathrm{mg} / \mathrm{kg}$ ) in rats was associated with increased ROS formation, myocyte necrosis, cardiomyocyte atrophy, vacuolar degeneration, and hemorrhage. ${ }^{2}$

In this present study, a single injection of DOX (25 mg/ $\mathrm{kg}$ ) was shown to trigger a significant elevation of cardiac injury biomarkers, demonstrating its deleterious effects on cardiac cells. Additionally, the toxic effect of DOX manifests in histopathological lesions, mostly portrayed by the presence of necrosis and atrophy of cardiomyocytes. The pre-treatment with either EVOO or VCO-EVOO combination in DOX-treated rats caused an attenuation of SGOT, LDH, and CKMB elevations. However, we found that the combination of VCO and EVOO was more effective to restore cardiac biomarkers to normal levels compared to the administration of EVOO as single preparation. Interestingly, in this study, although VCO could ease the increase of CKMB and LDH levels, it failed to improve the SGOT level in DOX-treated rats. A similar result was also depicted in the histopathological examination. It is shown that DOX-induced histological alteration was mostly improved with VCO and EVOO combination compared to VCO or EVOO alone. Indeed, the application of the oil combination before DOX injection apparently capable of preserving the normal features of cardiac muscle cells.

The health benefit of EVOO consumption has long been recognized due to the high concentration of monounsaturated fatty acids (MUFAs) content, especially oleic acid. Oleic acid increases plasma high density lipoprotein and reduce LDL cholesterol levels. ${ }^{24}$ For this reason, oleic acid is expected to prevent cardiovascular disease, which is the leading cause of death in industrialized countries. Previously, several studies have shown the cardioprotective effect of olive oil on DOXinduced cardiotoxicity. 18,25 This effect was bestowed by the antioxidative compounds contained in olive oil, ${ }^{10}$ including oleuropein and hydroxytyrosol.11,26 Instead of hindering anticancer activity of DOX, the antioxidant activity of EVOO was found to synergistically improve DOX effect as chemotherapy. ${ }^{27}$

VCO has also been known to provide benefits in eliminating stress, weight loss, lowering cholesterol and LDL levels, maintaining blood pressures, circulatory disorders, as an immunomodulator and anti-inflammatory agent.28,29 Indeed, VCO's benefits on endogenous antioxidant and defense mechanism have been known for years. ${ }^{30,31}$ These promising effects have placed VCO as one of the virtuous candidates for cardioprotective agents. Nonetheless, apart from studies focusing on VCO's hepatoprotective, antioxidant, and immunomodulatory effects, ${ }^{32-34}$ there is lack of studies that focus on VCO's cardioprotection against DOX toxicity.

In our study, it is demonstrated that VCO's cardioprotection against DOX toxicity was inferior compared to EVOO. Various studies have shown that the health benefits of EVOO are far beyond MUFA effects since EVOO is also rich in phenolic contents, tocopherol, squalene, phytosterols, triterpenoids, and $\beta$-carotene. ${ }^{35}$ Compared to coconut oil, olive oil was found to be superior in reducing atherosclerotic plaque in hamsters fed with a high-fat diet. ${ }^{36}$ Another study has also confirmed this result by showing better prevention of hepatic steatosis, insulin sensitivity, inflammation, and fatty acid oxidation in mice treated with olive oil compared to coconut oil. ${ }^{37}$ Having said that the important finding in this present study is that EVOO's protective effects were augmented when it was combined with VCO. The combination could significantly improve cardiac injury biomarkers as well as histological features of cardiac tissues compared to EVOO alone. It is believed that by combining VCO and EVOO, the antioxidant compounds contained in both oils may work synergistically to restrain the formation of free radicals and restore the antioxidant balance. This finding necessitates future studies to further investigate the enhanced benefit of EVOO by combining it with VCO as nutraceutical, especially to provide protection against DOX-induced cardiotoxicity.

\section{CONCLUSION}

The combination of VCO and EVOO (1:1) at $10 \mathrm{~mL} / \mathrm{kg}$ of rat body weight was superior to either VCO or EVOO alone in preventing the elevation of cardiac biomarker injury in DOX-treated rats. VCO and EVOO combination was found capable of recovering cardiac histopathological alteration due to acute toxicity of DOX.

\section{ACKNOWLEDGMENTS}

The authors want to thank Professor Elly Wahyudin, Professor Natsir Djide, and Yusnita Rifai, Ph.D for their valuable advice during the study.

\section{Ethics}

Ethics Committee Approval: All animal protocols were performed based on institutional guidelines for animal laboratory handling and registered under an institutional ethical clearance number of UH21020059 from the Ministry of National Education, University of Hasanuddin Faculty of Medicine, Health Research Ethics Committee.

Informed Consent: Not applicable.

Peer-review: Externally peer-reviewed.

\section{Authorship Contributions}

Concept: Y.Y.D, Design: Y.Y.D., B.P.P., Data Collection or Processing: A.U.U., Analysis or Interpretation: Y.Y.D., A.U.U., Literature Search: A.U.U., Writing: A.U.U., Y.Y.D., B.P.P.

Conflict of Interest: No conflict of interest was declared by the authors.

Financial Disclosure: The authors declared that this study received no financial support. 


\section{REFERENCES}

1. Thorn CF, Oshiro C, Marsh S, Hernandez-Boussard T, McLeod H, Klein TE, Altman RB. Doxorubicin pathways: pharmacodynamics and adverse effects. Pharmacogenet Genomics. 2011;21:440-446.

2. Borgatti A, Chemotherapy, in canine and feline gastroenterology, RJ Washabau, MJ Day, Editors. 2013, WB Saunders: Saint Louis:494-499.

3. Khattry N, Malhotra P, Grover A, Sharma SC, Varma S. Doxorubicininduced cardiotoxicity in adult Indian patients on chemotherapy. Indian J Med Paediat Oncol. 2009;30:9-13.

4. Sandamali JAN, Hewawasam RP, Fernando MACSS, Jayatilaka KAPW, Madurawe RD, Sathananthan PP, Ekanayake U, Horadugoda J. Anthracycline-induced cardiotoxicity in breast cancer patients from Southern Sri Lanka: an echocardiographic analysis. BioMed Res Int. 2020;2020:1847159.

5. Scully R, Miller A, Grant Y, and Lipshultz SE, Anthracycline, herceptin, and $\mathrm{CV}$ toxicity, in comprehensive toxicology (second edition), CA McQueen, Editor. Elsevier: Oxford. 2010;413-427.

6. Schaupp CM, White CC, Merrill GF, Kavanagh TJ. Metabolism of doxorubicin to the cardiotoxic metabolite doxorubicinol is increased in a mouse model of chronic glutathione deficiency: a potential role for carbonyl reductase 3. Chem Biol Interact. 2015;234:154-161.

7. Siraki AG, Klotz LO, and Kehrer JP, Free radicals and reactive oxygen species, in Comprehensive toxicology $3^{\text {rd }}$ edition), CA McQueen, Editor. Elsevier: Oxford. 2018;262-294.

8. Nurul-Iman BS, Kamisah Y, Jaarin K, Qodriyah HM. Virgin coconut oil prevents blood pressure elevation and improves endothelial functions in rats fed with repeatedly heated palm oil. Evid Based Complement Alternat Med. 2013;2013:629329.

9. Arunima S, Rajamohan T. Effect of virgin coconut oil enriched diet on the antioxidant status and paraoxonase 1 activity in ameliorating the oxidative stress in rats - a comparative study. Food Funct. 2013;4:14021409.

10. Rus A, Molina F, Ramos MM, Martínez-Ramírez MJ, Del Moral ML. Extra virgin olive oil improves oxidative stress, functional capacity, and health-related psychological status in patients with fibromyalgia: a preliminary study. Biol Res Nurs. 2017;19:106-115.

11. Umeno A, Takashima M, Murotomi K, Nakajima Y, Koike T, Matsuo T, Yoshida $Y$. Radical-scavenging activity and antioxidative effects of olive leaf components oleuropein and hydroxytyrosol in comparison with homovanillic alcohol. J Oleo Sci. 2015;64:793-800.

12. Djabir YY, Arsyad MA, Sartini S, Lallo S. Potential roles of Kleinhovia hospita L. leaf extract in reducing doxorubicin acute hepatic, cardiac and renal toxicities in rats. Pharmacogn Res. 2017;9:168-173.

13. Zakaria ZA, Rofiee MS, Somchit MN, Zuraini A, Sulaiman MR, Teh LK, Salleh MZ, Long K. Hepatoprotective activity of dried- and fermentedprocessed virgin coconut oil. Evid Based Complement Alternat Med. 2011;2011:142739.

14. Çömez MS, Cellat M, Özkan H, Borazan Y, Aydın T, Gökçek I, Türk E, Güvenç M, Çakır A, Özsoy ŞY. Protective effect of oleuropein on ketamine-induced cardiotoxicity in rats. Naunyn Schmiedebergs Arch Pharmacol. 2020;393:1691-1699.

15. Mnafgui K, Hajji R, Derbali F, Khlif I, Kraiem F, Ellefi H, Elfeki A, Allouche N, Gharsallah N. Protective effect of hydroxytyrosol against cardiac remodeling after isoproterenol-induced myocardial infarction in rat. Cardiovasc Toxicol. 2016;16:147-155.
16. Andreadou I, Sigala F, lliodromitis EK, Papaefthimiou M, Sigalas C, Aligiannis N, Savvari P, Gorgoulis V, Papalabros E, Kremastinos DT. Acute doxorubicin cardiotoxicity is successfully treated with the phytochemical oleuropein through suppression of oxidative and nitrosative stress. J Mol Cell Cardiol. 2007;42:549-558.

17. Nagy AC, GulAcsi-BArdos P, CserEp Z, Hangody L, Forster T. Late cardiac effect of anthracycline therapy in physically active breast cancer survivors - a prospective study. Neoplasma. 2017;64:92-100.

18. Kumral A, Giriş M, Soluk-Tekkeşin M, Olgaç V, Doğru-Abbasoğlu $S$, Türkoğlu Ü, Uysal M. Effect of olive leaf extract treatment on doxorubicin-induced cardiac, hepatic and renal toxicity in rats. Pathophysiology. 2015;22:117-123.

19. Samadi M, Haghi-Aminjan H, Sattari M, Hooshangi Shayesteh MR, Bameri B, Armandeh M, Naddafi M, Eghbal MA, Abdollahi M. The role of taurine on chemotherapy-induced cardiotoxicity: a systematic review of non-clinical study. Life Sci. 2021;265:118813.

20. Kumral A, Giriş M, Soluk-Tekkeșin M, Olgaç V, Doğru-Abbasoğlu S, Türkoğlu Ü, Uysal M. Beneficial effects of carnosine and carnosine plus vitamin $E$ treatments on doxorubicin-induced oxidative stress and cardiac, hepatic, and renal toxicity in rats. Hum Exp Toxicol. 2016;35:635-643.

21. Ludke A, Sharma AK, Bagchi AK, Singal PK. Subcellular basis of vitamin $C$ protection against doxorubicin-induced changes in rat cardiomyocytes. Mol Cell Biochem. 2012;360:215-224.

22. Djabir YY, Usmar U, Wahyudin E, Mamada SS, Hamka IRN, Putri DPS, Amalia I. Roles of vitamin $\mathrm{C}$ and vitamin $\mathrm{E}$ on doxorubicin-induced renal and liver toxicity in rats. Nusantara Med Sci J. 2016;1:16-23.

23. Angsutararux P, Luanpitpong S, Issaragrisil S. Chemotherapy-induced cardiotoxicity: overview of the roles of oxidative stress. Oxid Med Cell Longev. 2015;2015:795602.

24. Jimenez-Lopez C, Carpena M, Lourenço-Lopes C, Gallardo-Gomez M, Lorenzo JM, Barba FJ, Prieto MA, Simal-Gandara J. Bioactive compounds and quality of extra virgin olive oil. Foods. 2020;9:1014.

25. AlMalki WH, Shahid I. Characterization of antihypertensive and cardioprotective effects of extra virgin olive oil against doxorubicin induced cardiomyopathy in rats. J Pharm Pharmacogn Res. 2020;8:316326.

26. Omar SH. Oleuropein in olive and its pharmacological effects. Sci Pharm. 2010;78:133-154.

27. El-Kammar H, Ghazy SE. Synergistic effect of combined treatment with extra virgin olive oil and doxorubicin on squamous cell carcinoma cell line. Egypt Dent J. 2018;64:3407-3416.

28. Ma ZF, Lee YY. Virgin coconut oil and its cardiovascular health benefits. Nat Prod Commun. 2016;11:1151-1152.

29. Babu AS, Veluswamy SK, Arena R, Guazzi M, Lavie CJ. Virgin coconut oil and its potential cardioprotective effects. Postgrad Med. 2014;126:7683.

30. Famurewa AC, Ekeleme-Egedigwe CA, Nwali SC, Agbo NN, Obi JN, Ezechukwu GC. Dietary supplementation with virgin coconut oil improves lipid profile and hepatic antioxidant status and has potential benefits on cardiovascular risk indices in normal rats. J Diet Suppl. 2018;15:330-342.

31. Nevin KG, Rajamohan T. Beneficial effects of virgin coconut oil on lipid parameters and in vitro LDL oxidation. Clin Biochem. 2004;37:830-835. 
32. Silalahi J, Rosidah Y, Satria D. Virgin coconut oil modulates tCD4+ and tCD8+ cell profile of doxorubicin-induced immune-suppressed rats. Biomed Pharmacother. 2010;64:579-581.

33. Mustika M, Fachrial E, Girsang E, Lister INE. Effect of virgin coconut oil toward antioxidant endogen and stress oxidative on rats induced doxorubicin. In $20203^{\text {rd }}$ International Conference on Mechanical, Electronics, Computer, and Industrial Technology (MECnIT). 2020. IEEE.

34. Girsang E, Nasution AN, Lister INE. Comparison hepatoprotective effect of virgin coconut oil and Curcuma longa Linn against doxorubicin induced hepatotoxicity in wistar rat. In $20203^{\text {rd }}$ International Conference on Mechanical, Electronics, Computer, and Industrial Technology (MECnIT). 2020. IEEE.
35. Silenzi A, Giovannini C, Scazzocchio B, Varì R, D'Archivio M, Santangelo C, Masella R. Extra virgin olive oil polyphenols: biological properties and antioxidant activity, in Pathology, VR Preedy, Editor. Academic Press. 2020;225-233.

36. Mangiapane EH, McAteer MA, Benson GM, White DA, Salter AM. Modulation of the regression of atherosclerosis in the hamster by dietary lipids: comparison of coconut oil and olive oil. $\mathrm{Br} \mathrm{J}$ Nutr. 1999;82:401-409.

37. López-Salazar V, Tapia MS, Tobón-Cornejo S, Díaz D, AlemánEscondrillas G, Granados-Portillo O, Noriega L, Tovar AR, Torres N. Consumption of soybean or olive oil at recommended concentrations increased the intestinal microbiota diversity and insulin sensitivity and prevented fatty liver compared to the effects of coconut oil. J Nutr Biochem. 2021;94:108751. 